fectly. If the surgeon's apposition is properly attended to, the same is continued by the application of the splint.

Dr. Cole, Helena-It strikes me as being an extremely ingenious device. In the entire field of accidental surgery in minor matters there is nothing more troublesome, perhaps, than fracture of the nose with displacement, and to get a satisfactory result is sometimes exceedingly difficult, and if I understand rightly the application of this apparatus it should be a practical part of every surgeon's paraphernalia.

Dr. W. J. MAYO, Rochester, Minn.-I was very much inter ested in the splint of the Doctor, the external part I have never seen used in this connection. My brother, Dr. C. H. Mayo, has used a somewhat similar intra nasal splint in the elevation of depressed nasal fractures, and also a method of his own for the relief of sunken nose caused either by fracture or specific disease. In sunken nose he cuts obliquely through the septum and the depressed tissues behind and inside of the nose with a heavy chisel or cartilage knife, and elevating the septum introduces the splint, which allows sound union at a high level. In these cases the results have been excellent and continued so. Ths bevel of the cut surface enables the sliding upward of the depressed portion. The splint used by him consists of a similar piece of brass wire bent by a single turn into a coil, the two projecting ends being introduced into the nostrils, one along the floor, the other sprung up beneath the depression; the tension of the spring thus formed gives the necessary upward curve, one splint thus constructed and covered with iodoform gauze being introduced into each side and left for a number of days.

Dr. BRyant, Omaha - I think this invention of Dr. Hawes for holding down the nose after an injury, not only the best splint I have seen, but the only one. I have never seen one for this particular purpose. The difficulty in a majority of the cases where injury to the nose has been received, is not to hold the nose down, but to raise it up-probably 90 per cent. or more would have a depressed nose, instead of an elevated nose : but this seems to be an all-round splint, not only to hold it down but to elevate it. If I were to criticise this I think it would be in the portion that enters the nostril, and that criticism is not anything of value, it simply would be this: In many cases, make it larger in order to keep it in, and that could be done by winding the copper with thread or string and then using soft rubber over that. I believe soft rubber is the best thing to prevent irritation of the mucous membrane, and I think this [indicating] might be uncomfortable after using it any length of time-that is, I think it would.

Dr. HAwEs--In making some remarks upon the comments that have been made $I$ come first to the comment that the inside appliance is uncomfortable. Any man that has ever had any experience knows that nothing is very comfortable in the nose; whenever you push up there a lot of cotton or cloth it is uncomfortable--but that has hardly ever been an objection during the years it has been practiced; it would be customary to use a wad of cotton, which is a thousand times more uncomfortable than the other, which is much more efficient. One of the other criticisms was on account of using a hard brass substance that was liable to corrode. That I reply to with the statement that in the paper it was stated it should be covered with a soft rubber catheter. I want to call attention to another fact, that I have presented to you two splints, the second is an outgrowth of the first; the second can be used for all purposes that the first was used for, the first can not be used for the purpose for which the second is. The first is intended to draw down the nose when it has been drawn upward: the second is intended to raise the nose from the inside, which is wholly outside of the field intended as the proper field of the first. Dr. Mayo speaks of a method which I was not aware of ; I have never seen it mentioned in the books. It is very evidently an excellent method of raising these depressed noses. This one of mine, while I have never had an opportunity to raise depressed noses, I have no doubt will do exactly what the other one does. The person who is using the splint should have some knowledge of the anatomic form of the inside of the nose, and should then bend his wires so that they should fit that form in particular, and raise the nose to its normal and esthetic position. The comment of Dr. Bryant that it should be larger can be very easily attained by using a larger catheter instead of the little catheter--I peeled off and threw away the rubber that I had on the outside when I began to talk, to show you the wire. By using the larger catheter you can adapt it on the inside to a nose of any size that you desire. Another of our members inquires, Where can I get these splints? I have stated in the paper that all you have to do is to get a piece of wire and a pair of pincers. If you want something better you might go down to any of the instrument makers, or even to the common tinsmith, and by giving your ideas, you might get it made in a very few minutes--if you go

to the instrument maker it will cost you a dollar and a half

if you go to the tinsmith it will cost you ten cents. That is all.

The President - Can the surgeon readily make that second splint?

Dr. HAwES-I made one; I am not a tinker or son of a tinker. but I made one in a bungling sort of way. This I took to the tinker and asked him to make it, and he made it rather better. shapelier far than I can; you would have to take that second one to the tinker or tinsmith or instrument maker. I do not think it is wholly perfect, but that it is an embryo of a valuable instrument, a valuable appliance.

Dr. Reinenind, Sheboygan, Wis. - I would like to make a suggestion in regard to the enlargement of the intranasal portion. I think that can be done and made comfortable by winding around absorbent cotton and dipping that in melted parafin which can be impregnated with an antiseptic solution; a back ing of cotton cloth can be built up on the intranasal splint the parafin is hard enough to make sufficient pressure.

Dr. Harnden, Waverly, N.Y.--I think it would be in order that a vote of thanks of this Academy be extended to the Doctor for bringing to our attention the valuable instrument.

Motion seconded and unanimously carried.

\section{REMARKS ON THE TREATMEN'T OF FRACTURES.}

I ade at the Third Annual Meeting of the American Academy of Rail. way Surgeons, held at Chicago, Ill., Sept. $23,24,25,1896$. BY R. ORTEGA, M.D.

(HIEF SURGEON TO THE MHXICAN INTERNATIONAL RAILWAY CIUDAD PORFIRIO DIA, MEXICO.

I want to talk about a treatment or practice which gives the patient entire relief at once from pain and puts him in good condition for work as soon as the fracture is solid. As soon as a patient breaks a bone I make massage from the lower part of the fractured limb to the upper part; we commence to do the massage very gently just on the skin, with anything, oil, or soap and water, salve or vaselin to allow the hand to rub without hurting. Ten or fifteen minutes afterward we do the massage on the muscles, always from the end of the member up, never making pressure; in ten or fifteen minutes after the pain is gone and we can reduce the fracture without chloroform or pain. As soon as the fracture is reduced we roll it in a simple flannel bandage, from the end of the member upward; if it is in the arm we put the arm in a simple handkerchief from the neck; if it is in the upper arm, the weight of the arm is enough to keep the fracture in good position. And the next day we do the same treatment, a little massage and a little movement in all the joints of the broken limb. I have done this treatment for a year. I have had but few cases as my practice is very small. One boy about 18 years old, had a wheel from which he fell and broke his right arm in the middle with a compound fracture, the upper end of the humerus projecting through the skin. Dr. Lord reduced this fracture, put on a good dressing and an apparatus, and he called the next day to see the patient; the patient wanted to cross the river. I saw the boy with Dr. Lord; we took off the apparatus, the wound was in good condition, aseptic because the doctor had put a very nice and good dressing on. I told him I was going to take off the apparatus as soon as I brought the boy over the river. I did so and then applied a bandage, and made motion in the elbow and other joints and in fifteen days this boy was at work as before the injury. There was a compound fracture of the humerus and simple fracture of the ulna, and in fifteen days later the boy recovered and worked as before, all the bones completely healed. I had one day two cases; one a small 
boy about 6 years old, broke the humerus of the right time in order to learn better methods in lithotomy. arm, not a compound fracture; I applied massage at Then he went to London. There W. Hunter, Pringle once, and in ten days this little boy climbed trees and the operations of Pott, Bromfield and Hawkins and did almost everything. The same day in the engaged his attention for three months. From there shop, a workman broke his humerus in the middle, he went to Leyden and visited Albin and Gaub. and the fracture was displaced, I did massage and put In 1766 he turned back to Würzburg, where three the fracture in position and rolled it in a bandage, years later he received his degree. He assisted the and I left this arm without an operation; I did mas- professor of anatomy, surgery and obstetrics, Hüber, sage every day and about 20 days afterward this patient $\mid$ and the chief surgeon Stang, who now retired. After was in good condition. I do not remember the details their death he filled the two offices of city and country of other cases, but I want to call your attention to obstetrician (1779). He refused a call to Berlin as prothis treatment. It gives a little more trouble to the fessor of surgery, and surgeon in the Charité. The battle doctor but that does not count; the patient does not suffer and is able to work very soon. My company does not give wages to people when they are sick and I think this treatment is very good because it does not keep patients two or three months withont working; they can go to work in 15 or 20 days.

\section{SURGERY ONE HUNDRED YEARS AGO.} AN HISTORICAL STUDY

BY DR. GEORGE FISCHER.

DEDICATED TO THE GERMAN SURGICAL ASSOCIATION,

TRANSLATED FOR THE JOURNAL OF THE AMERICAN MEDICAL ABBOCIATION BY CARL H. VON KLEIN, A.M., M.D.

VIII.--PROFESSORS OF SURGERY AND PRACTICAL SURGEONS (WUNDAERZTE).

(Continued from page 29 .)

In October, 1765, two Germans traveling for study reached Leyden together. With the greatest kindness, their celebrated countryman, Albinus (born in Frankfort on the Oder), whose anatomic works and drawings surpassed anything which had hitherto been done in descriptive anatomy, opened to them his invaluable storehouse of specimens. The two young men, who here formed a bond of friendship which lasted through their whole lives, became later the best teachers of surgery, A. G. Richter and Carl Caspar von Siebold. The latter, who was six years the elder, was horn (1736-1807) in the little town of Nidecken, where his futher was a surgeon, and at the age of 16 he entered the school in Cologne, in order to study philosophy. There he made such good progress that he was enabled to take part in public disputations. In 1755 he returned to his father, who gave him instruction in surgery. When the "Seven Years' War" broke out Caspar entered the French army, which marched against the Hanoverians in Jülich. For three years he remained in the French field hospitals, where he had opportunities to perform operations. While in winter quarters he attended the lectures which were given by some French surgeons, according to official requirement. In 1760 he was stationed in Würzburg, became acquainted with the professors there, gave up his appointment and became assistant to Stang (later his father-in-law), who had been chief surgeon in Julius Hospital since 1731. Here he also attended theoretic and practical lectures for three years and then took his doctor's examination. The conferring of the degree was postponed, as the bishop-prince gave him money out of the university funds to enable him to travel. Siebold went to Paris (1763), remained there eighteen months, attaching himself chiefly to Morand, in the Invaliden Hôtel. He heard Sabatier, de la Faye, Bordenave, A. Petit and Levret, industriously practiced lithotomy on cadavers under Moreau, of Würzburg, in which Archduke Charles forced the retreat of the French, brought many wounded Austrians into Julius Hospital, and these were cared for by Siebold and his sons. As a recognition of his untiring activity, Emperor Francis II raised him and his descendants to the nobility of the Holy Roman Empire (1801). Soon after the bishop-prince advanced him from private-surgeon to private-physician, and the court-councillor promoted him from professor to privy-councillor. Siebold's activity in the various faculties was very extensive, yet he managed affairs with great energy. In the winter he lectured on anatomy, conducted the experiments in preparations, at first without a prosector by his side, lectured on operations and gave a course in operations. In the summer he lectured on bones and bandages. After New Year's he gave instruction to the midwives and frequently gave private lectures on the theory of obstetrics and diseases of the eye. He was also engaged in making a collection of surgical specimens and conducted the surgical clinic in Julius Hospital every day. For his relief he gave up obstetrics (1790) and had his son, J. Barthel, appointed extraordinary professor of anatomy and surgery (1797), who had had the special instruction of treating the patients in Julius Hospital with his father. When, in 1802, the government of the bishop-prince was abolished and the Bavarian kingdom set up in its place, a reorganization of the university, henceforward called Julius-Maximiliun University, was effected, and the chair of anatomy was separated from that of surgery. Carl Caspar and $J$. Barthel were appointed professors of surgery, and the former acted as director of the anatomico-surgical institute.

With C. C. von Siebold there began for Würzburg a new and brilliant epoch, such as the university had never before experienced, insomuch that at the end of the century Würzburg was considiered one of the first universities in Catholic Germany. Aside from the successes which Siebold achieved in behalf of his little fatherland through the founding of the surgical clinic, the improvement of obstetries, through his active part in the organization of Julius-Maximilian University, and through the elevation of the surgical profession in the eyes of physicians and of the public, it was especially upon his eminent qualities as a teacher that his reputation in Germany rested. After Göttingen came W turzburg, which had the advantage of possessing over the first mentioned and over other universities, a very large and beautiful hospital-the principal school for surgeons. Siebold attracted a great number of students, among them many foreigners, and he distinguished himself before his colleagues through the fact that he trained up a large number of academic teachers from his body of: and visited the Hôtel Dieu. In 1765 he visited assistants. Among these, besides his sons, were ProLe Cat in Rouen, and resided with him a longlfessors Weidmann and Fibig in Mainz;. Röвch in 